\title{
Interpenetrating Polymer Network of Poly(styrene) and Poly(citronellol-alt-methyl methacrylate). Synthesis and Characterization
}

\author{
Prachi PANDEY, Meet KAMAL, and A. K. SRIVASTAVA ${ }^{\dagger}$ \\ Department of Chemistry, H. B. Technological, Institute, Kanpur 208002, India
}

(Received October 5, 2001; Accepted February 1, 2002)

\begin{abstract}
Interpenetrating polymer network (IPN) based on poly(styrene) and poly(citronellol-altmethylmethacrylate) have been synthesized by using benzoyl peroxide as initiator and divinyl benzene as crosslinking agent, in xylene under an inert atmosphere of nitrogen. The scanning electron microscopy reveals a characteristic two phase morphology of linear polymer dispersed in the matrix of copolymer. The properties like percentage swelling, average molecular weight between crosslinks (Mc), are direct function of [copolymer] and initiator [benzoyl peroxide] whereas inverse function of concentration of monomer (styrene) and crosslinker (divinyl benzene). The differential scanning calorimetry gives two values of glass transition temperature at $64.09^{\circ} \mathrm{C}$ and $159.79^{\circ} \mathrm{C}$. The value of activation energy, calculated from thermogravimetric analysis, is $20 \mathrm{~kJ} \mathrm{~mol}^{-1}$.
\end{abstract}

KEY WORDS Morphology / Properties / Synthesis / Styrene / Citronellol /

Interpenetrating polymer networks (IPNs) come under the unique category of molecular blends. Important IPN applications include anionic-cationic exchange resins and piezodialysis memberanes in which the components are ionically charged. Increasing number of commerical products have been developed utilising the concept of IPN. These products range from high impact plastics, adhesives, vibration damping materials, high temperature alloys etc. Interpenetrating polymer network (IPN) is an intimate combination of two polymers, both in network form, atleast one of which is synthesised or crosslinked in the immediate presence of the other. ${ }^{1}$ The IPNs have following characteristic: ${ }^{2,3}$

(i) In presence of solvent an IPN swells but does not dissolve.

(ii) The IPNs show varying degrees of phase separation in morphology.

The field of IPN was laid down by Millar ${ }^{4}$ and persuaded by Sperling et al., ${ }^{5-7}$ Frisch $^{8,9}$ and Lipatov. ${ }^{10}$ There is splendid scientific literature concerning IPN's based on polyurethanes ${ }^{11}$ and epoxy resins. ${ }^{12}$ Reza et al. ${ }^{13}$ have reported the synthesis and morphology of IPN's containing copolymers of methylene-bisacrylamide and vinyl ferrocene. The reports on synthesis of IPN containing poly(acrylamide-co-acrylic) and poly(vinyl alcohols) $)^{14}$ have also been published.

Little work has been carried out for synthesis of IPN using only metal acrylate $(\mathrm{Zn}, \mathrm{Cu}, \mathrm{Cr}$ ) with vinyl monomers ${ }^{15,16}$ and IPN formation using two metal acrylates ${ }^{17,19}$ but, no work has been carried out in the synthesis of IPN using a copolymer of terpene with vinyl monomer crosslinked with metal acrylate. These

${ }^{\dagger}$ To whom correspondence shound be addressed. terpenes generally do not undergo homopolymerization but rarely undergo copolymerization. Recently we have reported synthesis of styrene-co-citronellol ${ }^{20}$ and vinyl pyrrolidinone-co-citronellol ${ }^{21}$ and therefore, extended our studies to the synthesis of IPNs. The present communication, therefore highlights synthesis and characterization of novel type mechanically strong and perfumed IPN of citronellol-alt-methylmethacrylate and poly(styrene).

\section{EXPERIMENTAL}

Purified solvent and divinyl benzene were used. Benzoyl peroxide was recrystallised in chloroform $(\mathrm{mp}=$ $\left.103^{\circ} \mathrm{C}\right)$.

\section{Synthesis of Copolymer}

The synthesis and characteristics of alternating copolymer of citronellol with MMA has been reported elsewhere. Briefly a solution containing citronellol $11.96 \times 10^{-1} \mathrm{~mol} \mathrm{~L}^{-1}$, methyl methacrylate $21 \times$ $10^{-1} \mathrm{~mol} \mathrm{~L}^{-1}$ and benzoylperoxide (BPO) $8.13 \times 10^{-3}$ mol L $\mathrm{L}^{-1}$ as initiator in xylene were kept for $1 \mathrm{~h}$ at $80 \pm 1{ }^{\circ} \mathrm{C}$ under an inert atmosphere of nitrogen. The copolymer was precipitated in methanol and dried to constant weight. It was then subjected to solvent (acetonitrile) treatment (to remove homopolymer) using soxhlet apparatus and then dried to constant weight.

\section{Synthesis of IPN}

A series of 16 IPNs were synthesized by systematic variation of concentration of citronellol-altmethylmethacrylate (Table I), styrene (Table II) using 
Table I. Effect of variation of CIT-alt-MMA on IPN

\begin{tabular}{ccccc}
\hline S.No. & $\begin{array}{c}\text { [CIT-alt-MMA } \\
\left.\times 10^{2} \text { (base } \mathrm{M}\right) \\
\mathrm{mol} \mathrm{L}^{-1}\end{array}$ & \% yield & $\begin{array}{c}\text { \% swelling } \\
\text { in DMF }\end{array}$ & $\begin{array}{c}\text { Mc } \\
\text { in DMF }\end{array}$ \\
\hline IPN-1 & 0.006 & 19 & 48 & 980 \\
IPN-2 & 1.30 & 24 & 56 & 1274 \\
IPN-3 & 1.95 & 36 & 77 & 2204 \\
IPN-4 & 2.60 & 55 & 85 & 2467 \\
IPN-5 & 3.25 & 58 & 93 & 2861 \\
\hline
\end{tabular}

$[$ Styrene $]=4.61 \mathrm{~mol} \mathrm{~L}^{-1} .[\mathrm{DVB}]=1.15 \mathrm{~mol} \mathrm{~L}^{-1} .[\mathrm{BPO}]=$ $1.37 \times 10^{-2} \mathrm{~mol} \mathrm{~L}^{-1}$. Temperature $=85 \pm 1^{\circ} \mathrm{C}$. Time $=1 \mathrm{~h}$.

Table II. Effect of (Styrene) on IPN properties

\begin{tabular}{lcccc}
\hline S.No. & $\begin{array}{c}\text { (Styrene) } \\
\text { mol L }^{-1}\end{array}$ & \% yield & $\begin{array}{c}\text { \% swelling } \\
\text { in DMF }\end{array}$ & $\begin{array}{c}\mathrm{M}_{\mathrm{c}} \\
\text { in DMF }\end{array}$ \\
\hline IPN-6 & 3.46 & 65 & 46 & 930 \\
IPN-7 & 4.03 & 56 & 38 & 719 \\
IPN-8 & 4.61 & 43 & 31 & 540 \\
IPN-9 & 5.19 & 32 & 25 & 399 \\
IPN-10 & 5.76 & 24 & 21 & 322 \\
\hline
\end{tabular}

$[\text { CIT-alt-MMA }]_{(\text {base } \mathrm{M})}=1.95 \times 10^{-2} \mathrm{~mol} \mathrm{~L}^{-1} .[\mathrm{BPO}]=$ $1.37 \times 10^{-2} \mathrm{~mol} \mathrm{~L}^{-1}$. [DVB] $=1.15 \mathrm{~mol} \mathrm{~L}^{-1}$. Temperature $=$ $85 \pm 1{ }^{\circ} \mathrm{C}$. Time $=1 \mathrm{~h}$.

Table III. Effect of (BPO) on IPN properties

\begin{tabular}{lcccc}
\hline \multicolumn{1}{c}{ S.No. } & $\begin{array}{c}(\mathrm{BPO}) \times 10^{2} \\
\mathrm{~mol} \mathrm{~L}^{-1}\end{array}$ & \% yield & $\begin{array}{c}\text { \% swelling } \\
\text { in DMF }\end{array}$ & $\begin{array}{c}\mathrm{M}_{\mathrm{c}} \\
\text { in DMF }\end{array}$ \\
\hline IPN-11 & 0.688 & 21 & 42 & 666 \\
$\mathrm{IPN}-2$ & 1.37 & 24 & 56 & 1274 \\
$\mathrm{IPN}-12$ & 2.06 & 32 & 62 & 1533 \\
$\mathrm{IPN}-13$ & 2.75 & 39 & 71 & 2122 \\
\hline$[\mathrm{CIT}-\text { alt }-\mathrm{MMA}]_{(\text {base } \mathrm{M})}=1.95 \times 10^{-2} \mathrm{~mol} \mathrm{~L}^{-1}$. & {$[$ Styrene $]=$} \\
$4.61 \mathrm{~mol} \mathrm{~L}$ \\
Time $=1 \mathrm{~h}$.
\end{tabular}

Table IV. Effect of (DVB) on IPN properties

\begin{tabular}{lcccc}
\hline S.No. & $\begin{array}{c}\text { DVB. } \\
\text { mol L }^{-1}\end{array}$ & \% yield & $\begin{array}{c}\text { \% swelling } \\
\text { in DMF }\end{array}$ & $\begin{array}{c}\mathrm{M}_{\mathrm{c}} \\
\text { in DMF }\end{array}$ \\
\hline IPN-14 & 0.615 & 17 & 68 & 1718 \\
IPN-2 & 1.15 & 24 & 56 & 1274 \\
IPN-15 & 1.43 & 28 & 45 & 950 \\
IPN-16 & 1.84 & 33 & 36 & 658 \\
\hline
\end{tabular}

$[\text { CIT-alt-MMA] }]_{(\text {base M) }}=1.95 \times 10^{-2} \mathrm{~mol} \mathrm{~L}^{-1}$.

$[$ Styrene $]=4.61 \mathrm{~mol} \mathrm{~L}^{-1}$. $[\mathrm{BPO}]=1.37 \times 10^{-2} \mathrm{~mol} \mathrm{~L}^{-1}$. Temperature $=85 \pm 1{ }^{\circ} \mathrm{C}$. Time $=1 \mathrm{~h}$.

BPO (Table III) as initiator and DVB (Table IV) as crosslinking agent, in xylene for $1 \mathrm{~h}$ under an inert atmosphere of nitrogen at $85 \pm 1{ }^{\circ} \mathrm{C}$.

The IPNs formed were precipitated in methanol and dried to constant weight.

\section{Characterization of IPN}

The soluble or uncrosslinked component was removed with the help of soxhlet extractor. The percentage extractable material is calculated according to the following relationship:

$$
\begin{aligned}
& \% \text { extractable material }=\frac{W_{\mathrm{b}}-W_{\mathrm{a}}}{W_{\mathrm{a}}} \times 100 \\
& W_{\mathrm{b}}=\text { weight of IPN before extraction } \\
& W_{\mathrm{a}}=\text { weight of IPN after extraction }
\end{aligned}
$$

\section{Swelling Properties}

Swelling data was calculated by soaking the sample in different polar and non polar solvents such as DMF, DMSO, dioxane, benzene, toluene until an equilibrium weight was achieved $(\sim 24 \mathrm{~h})$. Weight measurements were made by blotting the sample dry and immediately weighing them. The swelling solvent was then removed by heating the samples to $60^{\circ} \mathrm{C}$ under vacuum, until an equilibrium weight was achieved. The percentage swelling is calculated according to the following relationship. $^{22}$

$$
\begin{aligned}
& \% \text { Swelling }=\frac{W_{\mathrm{s}}-W_{\mathrm{d}}}{W_{\mathrm{d}}} \times 100 \\
& W_{\mathrm{s}}=\text { weight of swelled IPN. } \\
& W_{\mathrm{d}}=\text { weight of dry IPN. }
\end{aligned}
$$

\section{Crosslink Density $\left(1 / M_{\mathrm{c}}\right)$}

The crosslink density $\left(1 / M_{\mathrm{c}}\right)$ of the network was determined by using the swelling data of IPN in DMF with the help of Flory Rehner equation. ${ }^{23}$

$$
\frac{1}{M_{\mathrm{c}}}=-\frac{\ln \left(1-V_{\mathrm{p}}\right)+V_{\mathrm{p}}+X_{12} V_{\mathrm{p}^{2}}}{V_{1}\left(V_{\mathrm{p}}^{1 / 3}-V_{\mathrm{p}} / 2\right)}
$$

Where, $M_{\mathrm{c}}=$ average mol wt. of network between crosslinks

$V_{1}=$ molar volume of solvent

$V_{\mathrm{p}}=$ volume fraction of polymer in swollen gel.

$X_{12}=$ polymer solvent interaction parameter, calculated by the following expression.

$$
X_{12}=B+\frac{V_{1}}{R T}\left(\delta_{\mathrm{p}}-\delta_{\mathrm{s}}\right)^{2}
$$

Where $\delta_{\mathrm{p}}$ and $\delta_{\mathrm{s}}=$ solubility parameters of polymer and swelling solvent.

$B=$ lattice constant, the value of which is taken as $0.34 .{ }^{24}$

\section{SEM Morphology}

The morphology of the IPN's has been studied by the scanning electron microscopy (SEM) which has a resolution of $50 \AA$ and depth of field $30 \mu$. Sample were mounted on a SEM stub by graphite adhesive paste and coated with gold in a SEM coating unit. The samples were then scanned in a JEOL JSM 840 A scanning electron microscope (SEM). 


\section{Thermal Properties}

Measurements of glass transition temperature was carried out with a differential scanning calorimeter (V2.2A Dupont Model 9900). DSC curves were recorded under nitrogen atmosphere at a heating rate of $10{ }^{\circ} \mathrm{C} \mathrm{min}^{-1}$. The sample weight was $4.5 \pm 0.1 \mathrm{mg}$.

\section{Thermo-Gravimeteric Analysis (TGA)}

Thermogravimeteric analysis was carried on TGA V51A Dupont 2100 at heating rate of $10^{\circ} \mathrm{C} \mathrm{min}^{-1}$ under nitrogen atmosphere. The activation energy $\left(E_{\mathrm{a}}\right)$ and order of a reaction was calculated from Coats and Redfern equation. ${ }^{22}$

$$
\begin{aligned}
\log g(\alpha) / T^{2} & =\frac{E_{\mathrm{a}}}{2.3 R T}+\log \frac{Z A}{B E}\left(1-\frac{2 R T}{E_{\mathrm{a}}}\right) \\
g & =-\log [(1-\alpha) / n]
\end{aligned}
$$

Where $Z=$ pre exponential factor

$T=$ temperature

$B=$ linear heating rate

$R=$ gas constant

$A=$ Arrhenius factor

The plot of $\log \left[g(\alpha) / T^{2}\right]$ vs. $1 / T \times 10^{3}$ gives a linear curve, whose slope is equal to $-E_{\mathrm{a}} / 2.3 R T$ and its intercept corresponds to $\log _{10} 2 A / B \Delta E\left(1-2 R T / E_{\mathrm{a}}\right)$.

\section{RESULTS AND DISCUSSION}

\section{Characterization of Copolymer}

The copolymer of citronellol-alt-MMA was characterized by Infrared spectroscopy. The IR spectrum (Figure 1) of the copolymer shows bands at $3414 \mathrm{~cm}^{-1}$ for alcoholic group of citronellol and $1731 \mathrm{~cm}^{-1}$ for acrylate group of methylmethacrylate respectively. The FT-IR spectra of the copolymer shows bands at $1735 \mathrm{~cm}^{-1}$ for acrylate group of MMA at $3000 \mathrm{~cm}^{-1}$ for alcoholic group of citronellol (Figure 1). The $\mathrm{OH}$ group of citronellol in NMR appears in the range of 7 to $7.7 \delta$.

In order to calculate the reactivity ratios, the composition of citronellol content from the peak area of

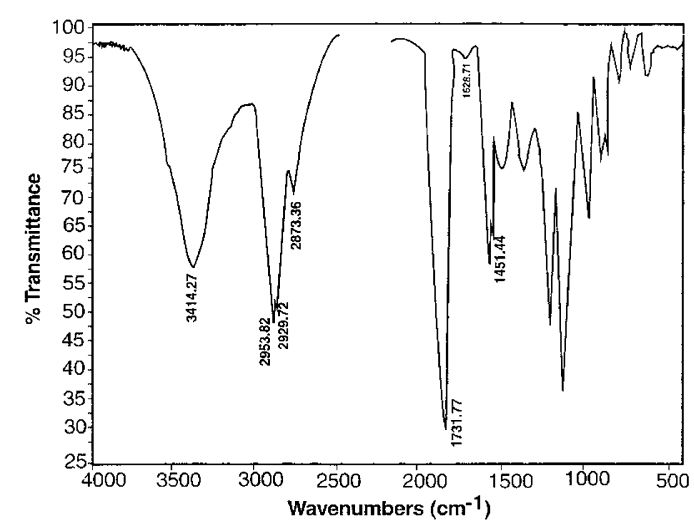

Figure 1. IR spectrum of the copolymer CIT-alt-MMA. hydroxy proton and methylmethacrylate content from the peak area of methoxy protons in the NMR spectra have been calculated (Table V). The values of reactivity ratios were calculated by Kelen Tudos method ${ }^{26}$ $r_{1}(\mathrm{MMA})=0.14$ and $r_{2}(\mathrm{CIT})=0.011$, respectively.

The proposed structure of the copolymer is as follows:<smiles>CCCC(C)CC(C)(CCC)C(C)(C)C(=O)OC</smiles>

\section{Characterization of IPN}

Infrared Spectroscopy. The IR spectrum of IPN is shown in (Figure 2). The presence of ester group is confirmed by characteristic bands at $1750 \mathrm{~cm}^{-1}$, alcholic group of citronellol at $3486 \mathrm{~cm}^{-1}$ and band of aromatic ring is observed at $3010 \mathrm{~cm}^{-1}$.

Effect of Composition. The study of effect of composition of copolymer results in increased swelling and Mc (Table I) with increase in concentration of copolymer. This implies that the presence of copolymer restricts crosslinking of polystyrene. This restriction is due to overall decrease in concentration of crosslink-

Table V. Composition of copolymers

\begin{tabular}{cccc}
\hline Sample & $\begin{array}{c}\text { Molar ratio in } \\
\text { monomer feed } \\
{[\mathrm{MMA}] /[\mathrm{CIT}]}\end{array}$ & Conversion \% & $\begin{array}{c}\text { Molar ratio } \\
\text { in copolymer } \\
\text { composition } \\
{[\mathrm{MMA}] /[\mathrm{CIT}]}\end{array}$ \\
\hline 4 & 1.75 & 7 & 1.00 \\
7 & 3.57 & 5.7 & 1.17 \\
8 & 1.17 & 8.1 & 1.05 \\
10 & 0.87 & 4.9 & 1.04 \\
11 & 2.63 & 8.3 & 1.13 \\
\hline
\end{tabular}

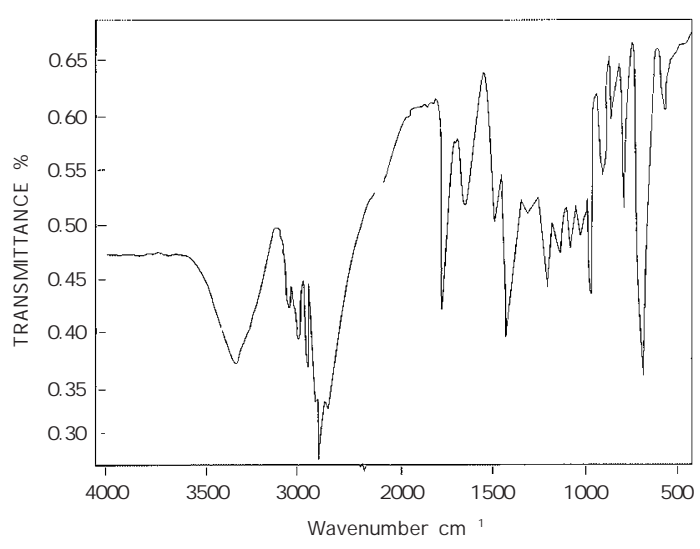

Figure 2. IR spectrum of IPN-2. 


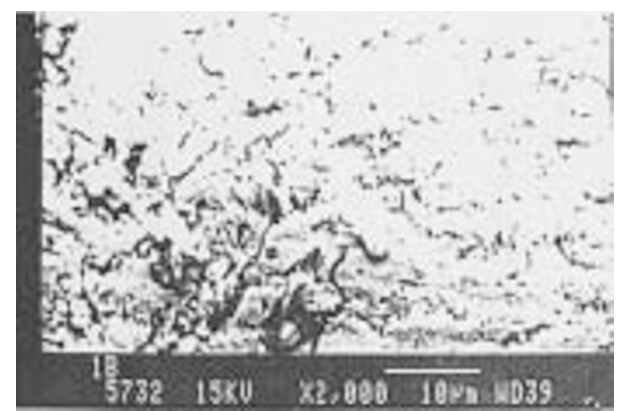

Figure 3. SEM photograph of IPN-2.

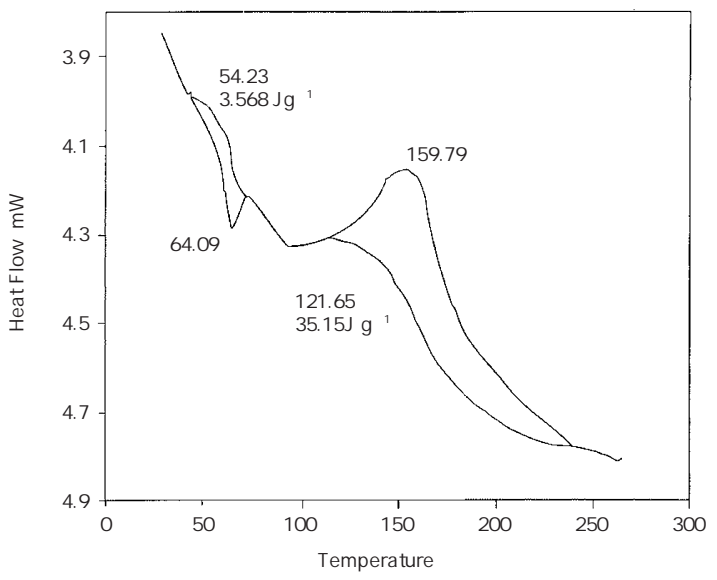

Figure 4. DSC curve of IPN-2.

ing site of styrene. As the concentration of copolymer increases the probability of grafting by styrene also increases which produces crosslinking between the two polymers. A similar explanation is given for the percentage swelling and Mc which are inverse function of styrene (Table II).

Effect of Crosslinker (DVB). Table IV shows that as the concentration of crosslinker DVB increase, the value of crosslinked density and precentage swelling decreases. The IPN does not dissolve, but swells in DMF. It is an evidence for cross-linking between two components.

Effect of Initiator (BPO). Table III presents the effect of concentration of benzoyl peroxide on swelling and Mc of IPN. The data shows that both swelling and Mc increase with increase of (BPO).

Morphology and Thermal Property. The scanning electron microscope is an excellent tool for the examination of surface morphology. The SEM study (Figure 3) reveals that IPN exhibit a characteristic morphology at a magnification of 2000 times indicating crosslinking between the two components. The result are in consequence with the DSC result (Figure 4) showing two glass transition temperature(s) $\left(T_{\mathrm{g}}\right)$ at $64.09^{\circ} \mathrm{C}$ and $159.79^{\circ} \mathrm{C}$.

Thermogravimetric Analysis. IPN sample containing (CIT-alt-MMA-polystyrene) is stable upto $426^{\circ} \mathrm{C}$

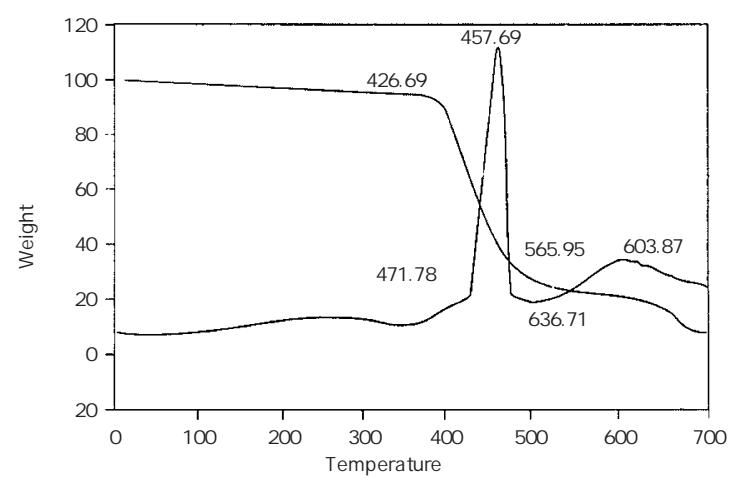

Figure 5. TGA curve of IPN-2.

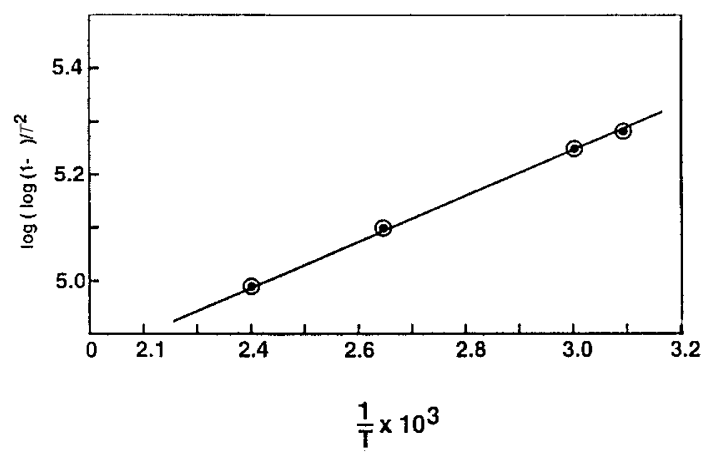

Figure 6. Graph plotted between $-\log \left[\log (1-\alpha) / T^{2}\right]$ vs. $1 / T \times 10^{3}$.

and started loosing weight above this temperature. Rapid decomposition is observed at $457^{\circ} \mathrm{C}-490^{\circ} \mathrm{C}$ and almost volatisation of polymer occured around $600^{\circ} \mathrm{C}$. Initial weight loss of $30 \%$ is observed around $400^{\circ} \mathrm{C}$ (Figure 5).

The activation energy, calculated from the slope of Linear graph plotted between $-\log \left[\log (1-\alpha) / T^{2}\right] v s$. $1 / T \times 10^{3}$ (Figure 6 ), is $20 \mathrm{~kJ} \mathrm{~mol}^{-1}$.

\section{CONCLUSIONS}

The major conclusions drawn are as follows :

1. $\mathrm{Mc}$ is direct function of (copolymer), (Initiator) where as inverse function of (Monomer) and (Crosslinker).

2. IPN exhibit characteristic morphology indicating crosslinking between the two components.

Acknowledgment. The authors are grateful to the Director, H.B.T.I., Kanpur for providing necessary facilities and also to Advanced Centre of Material Sciences, I.I.T., Kanpur, for providing SEM facilities. The authors are also thankful to DST, New Delhi for sanctioning the project "Synthesis and Characterization of copolymers of terpenes with vinyl monomers, SP/S1/H-26/Chem/2000". 


\section{REFERENCES}

1. L. H. Sperling, "IPN \& Related Materials, Division of Polym", Chemistry Nomenclature Committee Document, 1994.

2. L. H. Sperling, "IPN and Related Materials", Plenum, New York, N.Y., 1981.

3. L. H. Sperling, K. B. Farguson, J. A. Manson, E. M. Crowin, and D. L. Siegfried, Macromolcules, 9, 743 (1976).

4. J. R. Millar, J. Chem. Soc., 311 (1960).

5. A. A. Donatelli, L. H. Sperling, and D. A. Thomas, Macromolecules, 9, 671 (1976).

6. J. M. Widmair and L. H. Sperling, J. Appl. Polym. Sci., 27, 3525 (1982).

7. J. Soinakidi's, L. H. Sperling, and D. A. Thomas, J. Appl. Polym. Sci., 24, 1179 (1979).

8. S. Singh, H. L, Frisch, and H. Gniradella, Macromolecules, 23, 375 (1990).

9. H. L. Frisch, K. Gebreyes, and K. C. Frisch, J. Polym. Sci., Part A: Polym. Chem., 26, 3391 (1988).

10. Yu. S. Lipatov, O. P. Girigoreva, G. P. Kovernik, V. V. Sitov, and L. M. Sergeyeva, Makromol. Chem., 185, 347 (1984).

11. P. Patel and B. Suthar, Polymer, 31, 339 (1990).

12. N. Natchimuthu, P. Rajalingam, G. R. Krishnan, and D. I.
Francio, J. Appl. Polym. Sci., 41, 3059 (1990).

13. A. Reza, C. Benedetto, S. Lora, G. Palma, U. Russo, F. Sam, and M. Zeeca, Adv. Mater, 2, 412 (1990).

14. D. Dhara, C. K. Nisha, and P. R. Chatterjee, J. Macromol. Sci., Pure Appl. Chem., 36, 197 (1999).

15. N. Gupta and A. K. Srivastava, High Perform. Polym., 4, 225 (1992).

16. N. Gupta and A. K. Srivastava, Macromol. Rep., A30, 375 (1993).

17. N. Gupta and A. K. Srivastava, Macromolecules, 28, 827 (1995).

18. M. Kamal and A. K. Srivastava, J. Poly. Plastic and Engg., 40, 293 (2001).

19. M. Kamal and A. K. Srivastava, J. Macromol. Sci., Pure Appl. Chem., A37, 1627 (2000).

20. A. K. Srivastava and P. Pandey, Polym. Int., 50, 937 (2001).

21. P. Pandey and A. K. Srivastava, J. Polym. Res., in press.

22. P. R. Chatterjee, J. Appl. Polym. Sci., 37, 2203, (1989).

23. S. H. Pinner, "A Practical Course in Polymer Chemistry", Pergamon Press Inc., Tarrytown, N.Y., 1961, p 106.

24. E. A. Collins, J. Bares, F. W. Billmeyer, Jr., Experiment of Polym. Sci., John Wiley \& Sons, Inc., New York, N.Y., 1973, p 481.

25. A. W. Coats and J. R. Redfern, Nature, 201, 68 (1964).

26. T. Kelen and F. Tudos, J. Macromol. Sci. Chem., A9, 1 (1975). 